\title{
Status of forest-dwelling species nationally at risk in Canada $^{1}$
}

\author{
by Simon Nadeau ${ }^{2}$, Dawn Phillips ${ }^{3}$ and Eleanor Zurbrigg ${ }^{4}$
}

\section{Introduction}

A prerequisite to the conservation of biodiversity is the identification of the weaker links in the chain of multiple elements composing ecosystems. Species at risk of extinction represent examples of such fragile elements. These species are more sensitive to disturbances, by virtue of their small ranges often overlapping with intense human activities, narrow ecological requirements or relatively low reproductive potential. To quote Malcolm Hunter "Management for [...] special species, those threatened with extinction, clearly has a pivotal role in managing for diversity" (Hunter 1990).

One indicator of the conservation of biodiversity, as recognized by the Canadian Council of Forest Ministers in its definition of sustainable forest management, is the proportion of species that are threatened and endangered (Canadian Council of Forest Ministers 1995). This indicator is also embodied in the Sustainable Forest Management standards developed by the Canadian Standards Association (1996a, 1996b). This paper is a brief overview of the distribution of endangered, threatened and vulnerable species in Canada, with emphasis on forest-dwelling species and species affected or potentially affected by logging activities.

\section{The Canadian Process For Assessing Risk To Species}

The Committee on the Status of Endangered Wildlife in Canada (COSEWIC) was established in 1977 by the Federal-ProvincialTerritorial Wildlife Directors, to determine the national status of wild species, sub-species and nationally significant populations that may be at risk of extinction in Canada (from this point referred to as species). Categories of risk are: Extinct, Extirpated, Endangered, Threatened and Vulnerable. Assessments are based on status reports on candidate species. By 1997, 423 species had their status assessed by COSEWIC, and 67 were designated as endangered, 70 as threatened and 131 as vulnerable (COSEWIC 1997). The list of species will likely grow because the number of species assessed represents less than $0.6 \%$ of known Canadian species.

\section{Distribution of Species at Risk and Factors Affecting Them}

\section{Threatened and Endangered Species}

The distribution of species at risk can be analyzed using Canada's ecozone (CCEA 1996 - Fig. 1) and ecoregion

${ }^{1}$ Paper presented at the 79th Annual Meeting of the Canadian Woodlands Forum, CPPA, Montreal, Quebec, Canada, 24 March 1998.

${ }^{2}$ Science advisor, Recovery of species at risk, Endangered Species Conservation Division, Canadian Wildlife Service, Environment Canada, 351 St-Joseph Boulevard, 3rd floor, Hull, Quebec, Canada.

${ }^{3}$ GIS Technician, Environment Canada, 351 St-Joseph Boulevard, 3rd floor, Hull, Quebec, Canada.

${ }^{4}$ Chief, Endangered Species Conservation Division, Canadian Wildlife Service, Environment Canada, 351 St-Joseph Boulevard, 3rd floor, Hull, Quebec, Canada.

\section{COSEWIC Definition of Species and Risk Categories}

Species: Any indigenous species, sub-species, variety or geographically defined population of wild fauna and flora.

Extinct: A species that no longer exists.

Extirpated: A species no longer existing in the wild in Canada, but occurring elsewhere.

Endangered: A species facing immiment extirpation or extinction.

Threatened: A species likely to become endangered if limiting factors are not reversed.

Vulnerable: A species of special concem because of the characteristics that make it particularly senstive to human activities or natural events.

framework (Ecosystem Stratification Working Group 1995; see also description of zones and regions on Environment Canada Internet site at: http://wwwl.ec.gc.ca/ ecozones/). One hundred and twelve threatened and endangered (T\&E) species occur in the main forest ecozones, i.e., Atlantic Maritime, Mixedwood Plains, Boreal Shield, Boreal Plains, Pacific Maritime and Mountain Cordillera. Of these species, 44 (39\%) are forest-dwelling species. The huge Boreal Shield ecozone that spans over six provinces contains seven forest-dwelling T\&E species (Fig. 2) while the Mixedwood Plains has 25. The threats identified in the COSEWIC status reports were used to determine a species' susceptibility to logging. From these data it appears that the percentage of forest-dwelling $T \& E$ species susceptible to logging - that is affected or potentially affected by logging-related activities - in the six main forest ecozones varies between $0 \%$ in the Boreal Plains to $71 \%$ (5) in the Boreal Shield, with an average of $47 \%$ overall. The highest number of forest-dwelling T\&E species susceptible to logging occurs in the Mixedwood Plains (16). The Mixedwood Plains ecozone covers the southern half of Ontario and the St. Lawrence valley. Only $38.6 \%$ of this ecozone remains forested, and less than $3 \%$ is protected in parks and reserves, while it contains $51 \%$ of the Canadian population (CCEA 1996).

At least 11 of the $16 \mathrm{~T} \& \mathrm{E}$ fish species depend on clear water. Fish species were not included in the figures and maps in order to focus on forest-dwelling species rather than forest-dependent species. However, removal of trees along stream banks can lead to increasing water temperatures and siltation, thus potentially affecting fish habitat, especially for those species requiring cold, highly oxygenated clear water, such as salmonids.

Figure 3 represents the distribution of all COSEWIC threatened and endangered species by ecoregion. The ecoregion map allows refinement of the analysis done at the ecozone level. For 


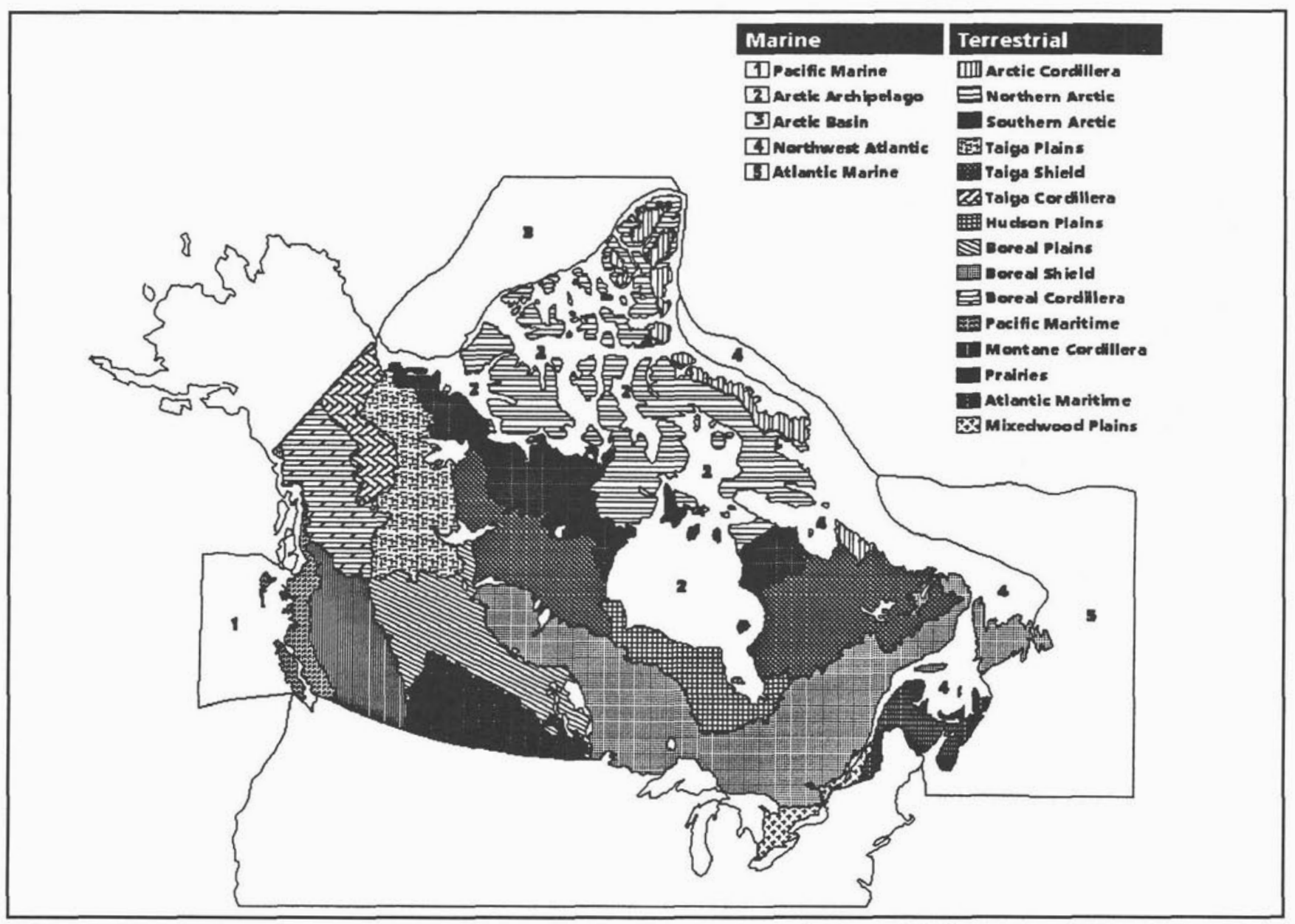

Fig. 1. Marine and Terrestrial Ecozones of Canada. (From Canadian Council of Ecological Areas 1996.)

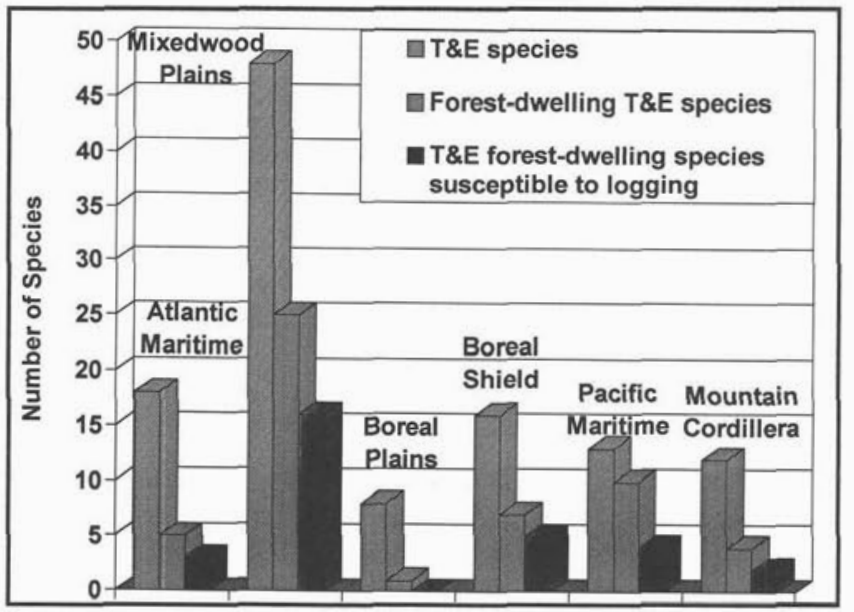

Fig. 2. Number of endangered and threatened species by ecozone.

example, ecoregions in the central portion of the Boreal Shield ecozone, in the north of the Mountain Cordillera and in the south of the Boreal Cordillera do not harbour T\&E species. Fortythree of the $48 \mathrm{~T} \& \mathrm{E}$ species in the Mixedwood Plains ecozone occur in the Lake Erie Lowland ecoregion of Southern Ontario. This ecoregion is more or less equivalent to the Deciduous forest region or Carolinian Canada.
Figure 4 shows the same information, but for T\&E forestdwelling species only. Most T\&E forest-dwelling species are located on the eastern and western ends of the country while central Canada contains very few if any. The two ecoregions with the highest numbers of T\&E forest-dwelling species are in southern Vancouver island and southern Ontario. Twentytwo $(54 \%)$ of all T\&E forest-dwelling species in Canada are restricted to the Lake Erie Lowland ecoregion. The Lake Erie Lowland region contains 14 of the 16 T\&E species susceptible to logging activities present in the Mixedwood ecozone. This ecoregion is densely populated, and a very significant proportion of the forested landscape has been cleared for agriculture and urbanization purposes. Logging activities in the remaining fragmented forest patches add to the stress of forest-dwelling species in this area.

Generally, the range distribution of T\&E species is relatively small (average $=53,910 \pm 762,002 \mathrm{~km}^{2}$ ) compared to the range of vulnerable species $\left(208,904 \pm 184,422 \mathrm{~km}^{2}\right)$, but both vary considerably among species and taxonomic groups. Species like the threatened Wood Poppy and the endangered Acadian Flycatcher in Southern Ontario occupy very small areas. However, there are notable exceptions where an endangered species has a large range, such as the endangered Eastern Wolverine in Quebec and Labrador and the endangered Anatum Peregrine Falcon throughout Canada. These species occur in very low densities in most of their present, range. 


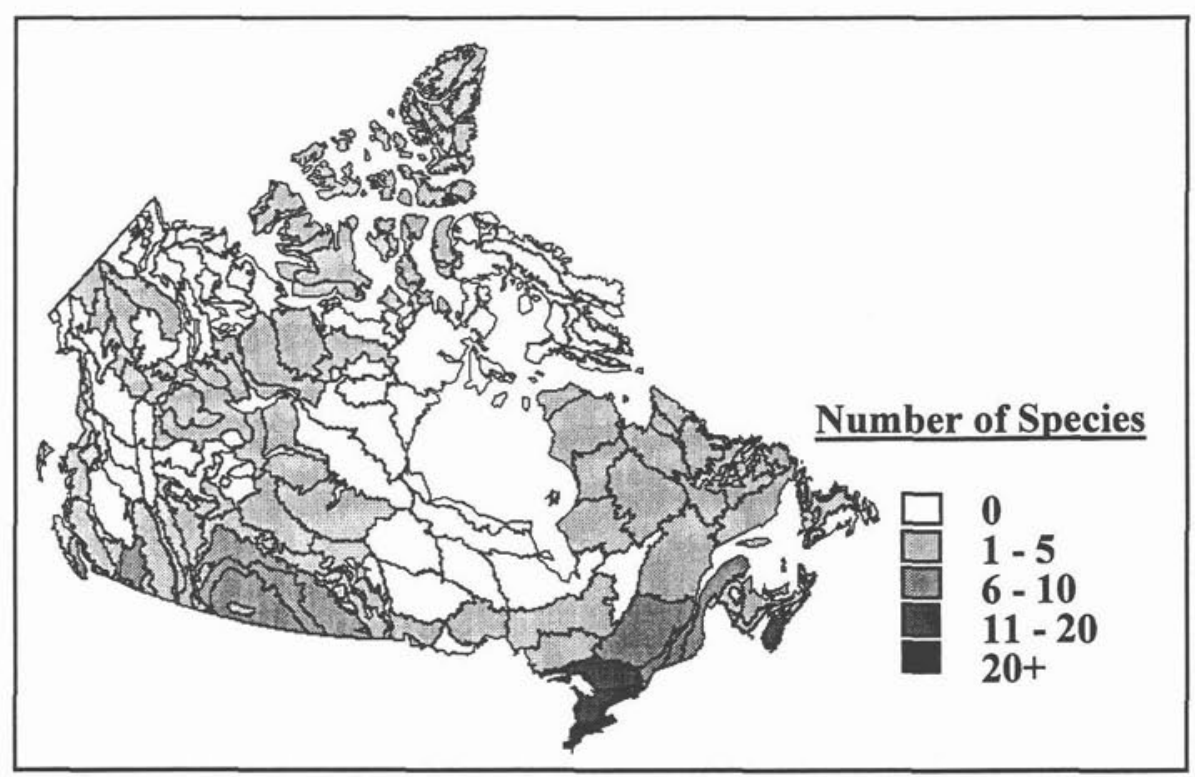

Fig. 3. Endangered and threatened species by ecoregion.

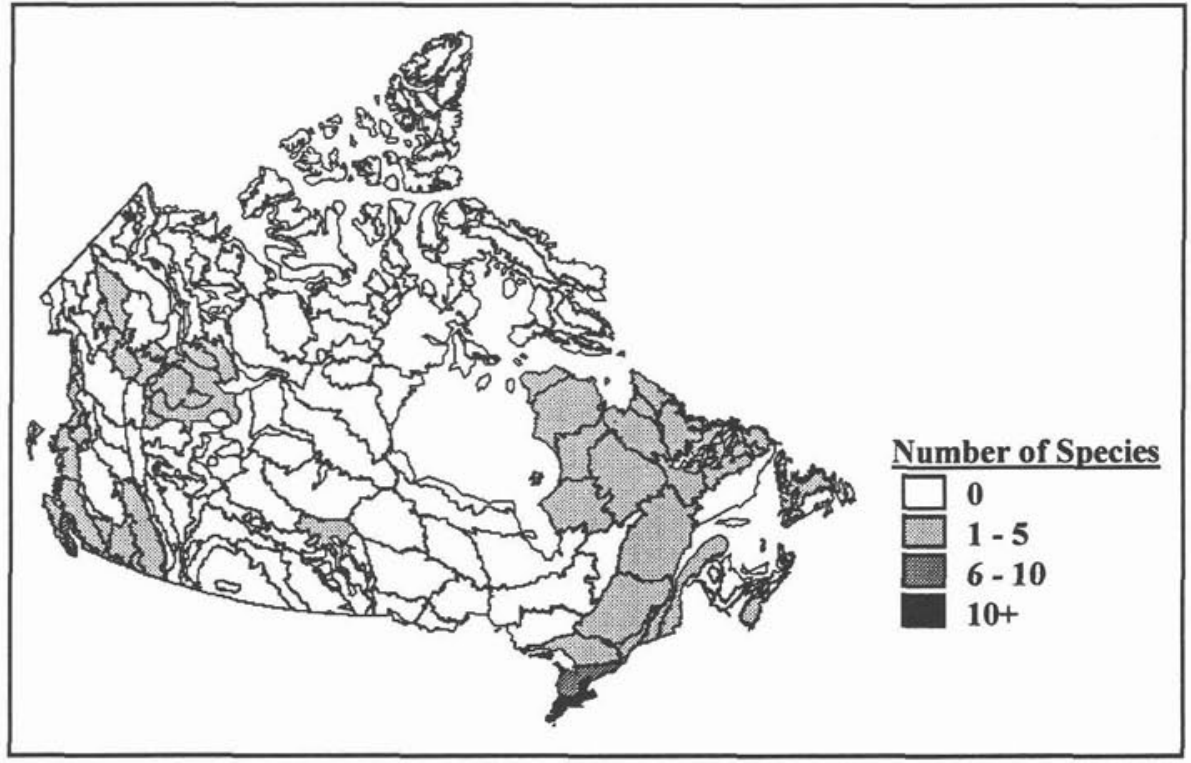

Fig. 4. Endangered and threatened forestdwelling species by ecoregion.

\section{Risk Factors}

A number of factors contribute to species decline and increase risk of extinction. The most important threat is the permanent loss of species' habitats, confining populations to fragmented smaller patches of habitat. This fragmentation decreases the possibility of genetic exchange between populations, especially for sedentary species such as plants like the American Ginseng. Inbreeding can then lead to reduced fitness for these small populations. Reptiles, such as the threatened Massassauga Rattlesnake, suffer from habitat fragmentation due to their relative sedentarism. Small populations are also more susceptible to threatening factors that would otherwise be insignificant from a conservation point of view for larger populations (e.g., diseases, predation, incidental killing).

A second risk factor is degradation in habitat quality, which can often be reversed through appropriate management. Examples for the forested landscape include the endangered Newfoundland Marten, a species that depends on mature for- est stands. Overharvesting has led to a rarity of mature stands in Newfoundland, which, combined with the larger marten territories on the island - in part due to a poorer prey base compared to its mainland counterpart - and incidental capture in snares set for hares, are endangering the marten.

In central Canada, the Kirtland's Warbler depends on young Jack Pine stands for foraging purposes. Typical forest management practices have been to clearcut mature Jack Pine stands. This alone would lead to the gradual loss of Jack Pine forests. Because Jack Pine cones generally require fire to release their seeds, a traditional method used to regenerate those stands where fire is controlled has been to replant them with Jack Pine. This method is partially inadequate to regenerate habitat for the Kirtland's Warbler because all trees will be of the same age and stands quickly become unsuitable for the warbler. This is very different from the action of fire that often leaves stands with live trees and releases Jack Pine seeds that will produce young trees and thus uneven-age stands. Silvicultural techniques to maintain this bird's habitat could combine uneven-age 


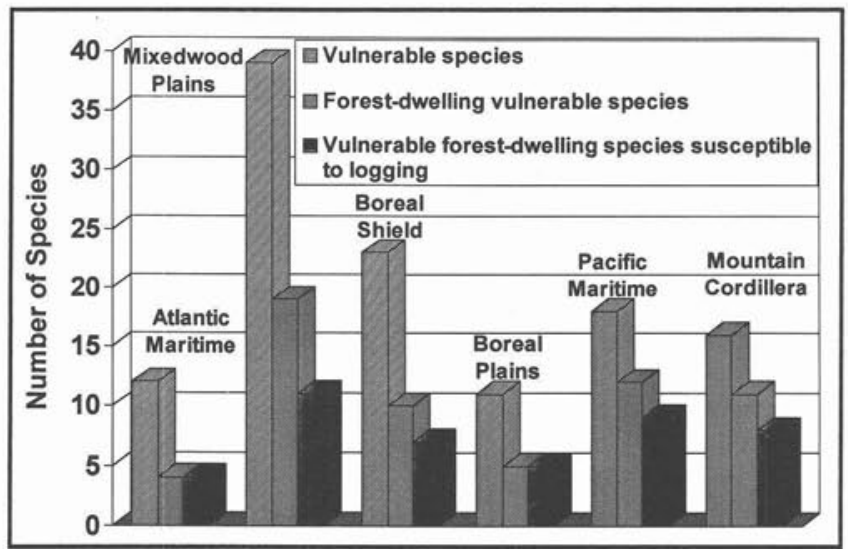

Fig. 5. Number of vulnerable species by ecozone.

management, as is prescribed for hardwood forests, combined with tree planting.

Other forest-dwelling species affected by disruption of the natural fire process include a suite of plant species inhabiting the Garry oak ecosystem in southern Vancouver Island, such as the threatened White-top Aster and the endangered Deltoid Balsamroot. Additional examples of threatened and endangered species affected by reduction in forest structure diversity include the Prothonotary Warbler of Southern Ontario and the Seaside Centipede Lichen in BC.

At the other extremity of the country, the spotted owl is another example of a species affected by habitat degradation that can not be easily repaired through appropriate silviculture. The Spotted Owl depends on the forest structure typical of old-growth stands in the Pacific Northwest. These stands are characterized by uneven-aged distribution, an important cohort of mature and over-mature trees, and specific biodiversity. These older stands occupy an increasingly smaller proportion of their original area, although a number of conservation areas have been set aside in the US and in Canada to prevent the Spotted Owl extinction. At least seventy-nine species of vertebrates depend on old-growth forest in British Columbia, but only $9.3 \%$ of the original BC old-growth forest remained in 1989 (The State of Canada's Environment 1991).
Invasive alien species represent an important threat to species at risk, whether they are diseases such as the Chestnut Blight that resulted in the endangerment of the American Chestnut in southern Ontario or competing tree species such as the introduced White Mulberry competing with the native Red Mulberry. Disease is also a factor for the Wood Bison in the northern prairies and Northwest Territories. The species is currently threatened by introduced brucellosis and tuberculosis.

Predation is a problem for some species. For example, increasing native raccoon populations are taking their toll of several turtle species, including the threatened Blanding's Turtle in Nova Scotia.

Historically, hunting and harvesting have been important factors explaining the endangerment of species such as Woodland Caribou, Eastern Cougar and American Ginseng and the extinction of others such as the Passenger Pigeon.

\section{Vulnerable Species}

Vulnerable species represent a different situation than T\&E species. Their extinction is not foreseen, but their biological characteristics make them sensitive to natural and human-induced disturbances. The number of vulnerable species in ecozones is more evenly distributed than for T\&E species, varying between 11 and 39 species among the six main forest ecozones (Fig. 5). The percentage of vulnerable forest-dwelling species affected or potentially affected by logging-related activities is even more uniform across ecozones than for T\&E species, varying between $58 \%$ and $100 \%$, with an average of $79 \%$. Figure 6 shows that most of the 217 ecoregions harbour vulnerable species. The analysis of Figs. 4 and 6 shows that only seven ecoregions do not contain any forest-dwelling species that are nationally at risk. Vulnerable species such as the Western Wolverine and the Grizzly Bear, that have ranges spanning across a wide latitudinal gradient, are responsible for the colouring of non-forested northern ecoregions. Canada has a high global responsibility for species such as the Grizzly Bear because $80 \%$ of the global population lives in British Columbia and the Yukon.

Examples of forest-dwelling vulnerable species include the Southern Flying Squirrel that occurs in Nova Scotia, southwestern Quebec and Southern Ontario. It is considered

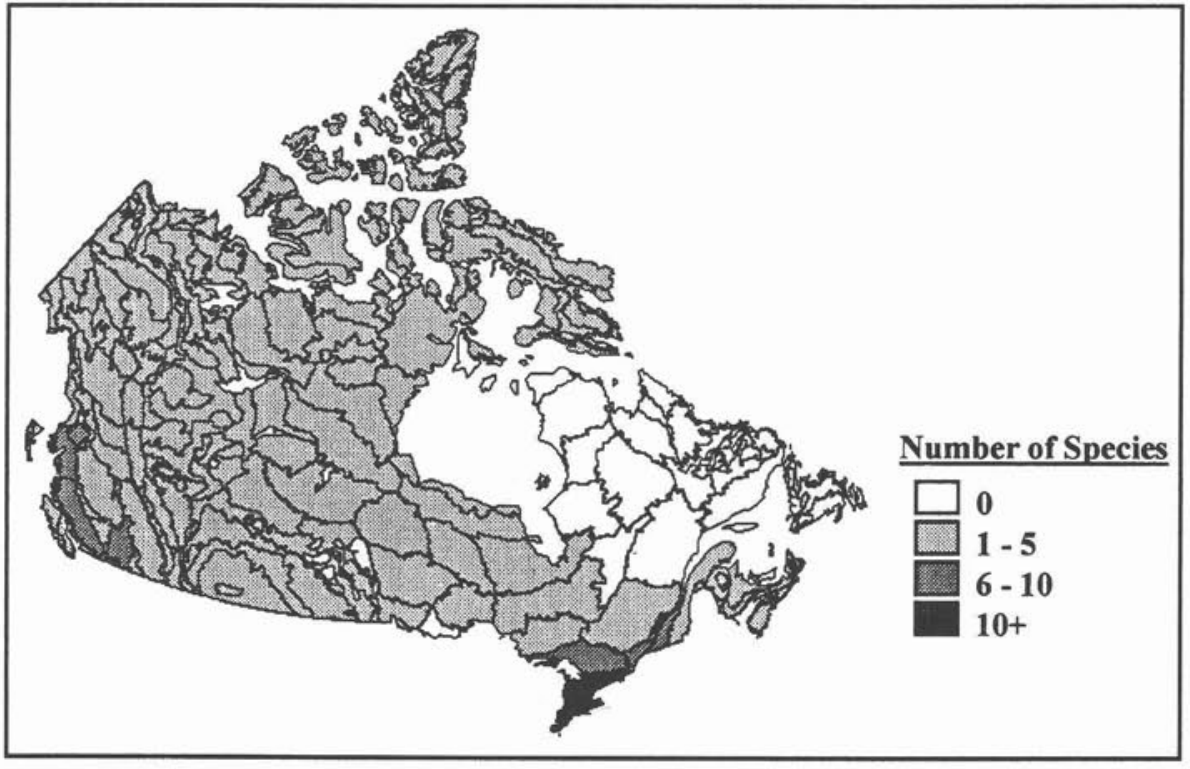

Fig. 6. Vulnerable forest-dwelling species by ecoregion. 
to be a secondary cavity nester as it needs tree cavities created by other species, generally woodpeckers. Trees with cavities are more frequent in mature and overmature stands. Leaving dead and live trees having cavities and clumps of live mature trees - especially of tree species preferred by woodpeckers for cavity excavation - is an appropriate forest management technique that will speed up the suitability of regenerating forests for cavity-using species. Examples of cavity users include the vulnerable Keen's Long-eared Bat - a species that has most of its global range in British Columbia - and the endangered Prothonotary Warbler of southern Ontario. Mature trees also maintain potential nesting structures for forest raptors. Modification of the forest landscape may trigger a series of changes with repercussions for species at risk. Logging activities and increasing areas affected by forest fires have rejuvenated some forest landscapes, creating favourable conditions for common ungulate species such as White-tailed Deer and Moose. Increased populations of these species in turn will support higher populations of their predators, Timber Wolf and Coyote, which will then increase the predation pressure on less numerous vulnerable species such as the Woodland Caribou, especially if populations of the common preys suddenly drop.

\section{Re-assessment of Species at Risk Status}

COSEWIC tries to re-assess its species' designations every ten years. Nine forest-dwelling species had their status re-assessed. The Cooper's Hawk, Eastern Bluebird and Great Gray Owl have been delisted while the Wood Bison, numbering now around 2500 individuals, compared to 450 in 1978 , has been downlisted from endangered to threatened in 1988. Three species have been uplisted to the endangered category, the Newfoundland Marten, Prothonotary Warbler and endemic Vancouver Island Marmot, while the Grizzly Bear was uplisted to vulnerable. The Louisiana Waterthrush, designated a vulnerable species in 1991, was reconfirmed as vulnerable in 1996.

\section{What Are We Doing for Forest-dwelling Species at Risk?}

Recognizing that a concerted approach was desirable for effectively conserving species at risk, all ministers responsible for wildlife in Canada ratified the RENEW (Recovery of Nationally Endangered Wildlife) Strategy in 1988 (Canadian Council of Wildlife Ministers 1988). The strategy calls for the production and implementation of recovery plans for each terrestrial vertebrate species designated as threatened and endangered, and to reintroduce extirpated species where feasible. The Strategy was eventually to be expanded to all taxonomic groups.
Currently, recovery teams are in place for all of the seventeen forest-dwelling T\&E terrestrial vertebrate species, 13 of those having draft or final recovery plans in place, and recovery actions have been taken for 10 species. Forest companies have been involved in the recovery of four of these $10 \mathrm{~T} \& \mathrm{E}$ species. While there is a potential for foresters and wildlife biologists working for the forest sector to become more involved in the recovery of T\&E species, there is undoubtedly more potential for involvement in managing vulnerable species. Appropriate considerations of vulnerable species in sustainable forest management plans and practices would ensure that these species continue to fulfill their ecological role for the benefit of present and future generations. Dealing with species before they reach critical population levels characteristic of T\&E species also allows for more management flexibility in possible conservation options.

The expansion of Canadian recovery efforts to all taxonomic groups for T\&E species and the need to prevent species from becoming at risk as called for in the National Accord for the Protection of Species at Risk (Wildlife Ministers Council of Canada 1996), will require an increasing participation from the forest sector. It is a concrete opportunity to apply the principles of sustainable forest management.

\section{References}

Canadian Council of Forest Ministers. 1995. Defining sustainable forest management: A Canadian approach to criteria and indicators. Ottawa. 22 p.

Canadian Council of Wildlife Ministers. 1988. RENEW: A strategy for the recovery of nationally endangered wildlife. Ottawa. $12 \mathrm{pp}$. Canadian Council on Ecological Areas (CCEA). 1996. A perspective on Canada's ecosystems. E.B. Wiken, D. Gauthier, I. Marshall, K. Lawton and $\mathrm{H}$. Hirvonen (eds.) Occasional paper No. 14. 95 p.

Canadian Standards Association. 1996a. A sustainable forest management system: Specifications document. CAN/CSA - Z809-96. Canadian Standards Association. 1996b. A sustainable forest management system: Guidance document. CAN/CSA - Z808-96.

Committee on the Status of Endangered Wildlife in Canada (COSEWIC). 1997. Canadian Species at Risk-April 1997. Ottawa. $19 \mathrm{p}$.

Ecosystem Stratification Working Group. 1995. A national ecological framework for Canada. Agriculture and Agri-Food Canada/Environment Canada. Ottawa. ISBN 0-662-24107-X.

Hunter Jr., M. L. 1990. Wildlife, forests and forestry: principles of managing forests for biological diversity. Regents/Prentice Hall. Englewood Cliffs. 370 p.

The State of Canada's Environment. 1991. Minister of Supply and Services Canada. ISBN 0-660-14237-6.

Wildlife Ministers' Council of Canada. 1996. National Accord for the Protection of Species at Risk. Charlottetown, PEI. 2 p. 